\title{
USES OF METADISCOURSE IN A RESEARCH ABSTRACTS FOR SCIENTIFIC EVENTS
}

\author{
Javier García-Calvo*
}

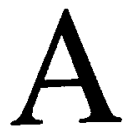

bstracts are commonly identified by the economy and precision of language. This type of text has as its main function to help readers learn about the most important aspects of a research study. In this sense, the abstract becomes a powerful tool to keep the scientific communities up-to-date.

Yet, when a research abstract is sent to a conference to be evaluated, or when it is published in the book of abstracts for a scientific event, it acquires an additional function: to persuade the reader about the importance of the study, in order to both have the paper accepted by the selecting committee and to lure the audience into attending the presentation. In this case, the abstract is not only the means to inform about the content of a research study, but also a vehicle for arousing the curiosity and interest of the reader.

Although contemporary research on abstracts has focused on diverse areas such as reading comprehension (Hartley, 1987), discourse structure (Graetz, 1985; Harvey, 1986; Day, 1988, Gartland, 1993), and the form and function of abstracts in the area of Medicine (Salager-Meyer, 1990, 1991, 1992), the characterization of abstracts as persuasive texts has been proposed only recently. According to researchers such as Kaplan, Singer, Hagstrom, Kamhi-Stein, Shiotani, and Zimmerman (1994), Bolivar (1996, 1997a, 1997b, 1998), and García-Calvo (1997,

* Universidad Central de Venezuela. 
1999, 2000), research abstracts for scientific events reflect the writer's need to interact with the reader, to convince him/her of the importance of the study, to persuade him/her to go to the presentation to establish a dialogue with the researcher.

Kaplan et al. (1994) carried out a study, using a corpus of 294 abstracts in the area of applied linguistics. For their analysis, five different aspects were taken into account: thematic structure, clause structure, pragmatic movements, propositional organization, and lexical cohesion. Among the characteristics proposed to identify abstracts, the researchers suggest that these types of texts do not provide an objective synthesis of a research study, but, rather, supply arguments to convince the selection committees on the relevance of research (Kaplan et al., 1994). In addition, these investigators found that conference abstracts reflect strategies in which the investigator establishes his/her position with regard to (a) the public presentation of the study, (b) the research paradigm, and (c) the world around him/ her. However, scarce references exist on the actual elements of abstracts that have a persuasive character. ${ }^{1}$

Bolívar (1996, 1997a, 1997b, 1998) has also analyzed conference abstracts in the area of linguistics. She has been interested in, among other aspects, the way in which abstracts reflect the interaction between the writer and the reader through the text. Bolivar (1997a) proposes that "conference abstracts are built interactively and that a special interest exists in presenting evaluations in all the sections of the texts" (p. 70). These evaluations have the function of convincing the reader about the relevance of the study.

García-Calvo $(1997,1999,2000)$ has been interested in the analysis of abstracts for scientific events. His studies have focused on the analysis of the internal structure of abstracts and on the various styles used by writers. He has found that abstracts have certain elements that characterize them as persuasive texts, such as promising information not presented in the text but judged as important by the writer, as well as the use of hedges. As a consequence, García-Calvo (1997) suggests that further research be carried out to explore the ways the writer constructs the abstract and transforms it into a persuasive text.

Additional researchers have studied the mechanisms of persuasion in other types of texts. Crismore, Markkanen and Steffensen (1993), for example, have analyzed the use of metadiscourse in persuasive compositions written by American and Finnish university students for the purposes of observing the influence of culture and gender on the use of metadiscourse strategies. According to these researchers, 
metadiscourse allows the writer to, among other things, express his/her attitude towards text content and his/her possible reader; that is, the author uses metadiscourse to make evaluations about what he/she writes and to convince the reader about the importance of the position assumed in the abstract and the study as a whole.

Crismore et al. (1993) used a corpus of persuasive texts, since these tend to concentrate more elements of metadiscourse than other types of texts. ${ }^{2}$ They analyzed the corpus by looking at the discourse markers used to signal both textual metadiscourse ${ }^{3}$ and interpersonal metadiscourse. The results of this study revealed that both American and Finnish students use all of the categories of metadiscourse proposed, and that there were also cultural differences with regard to the quantity and types of discourse markers used.

The study by Crismore et al. (1993) suggests that, because the abstract has been defined as a persuasive text, it would be beneficial to study the metadiscourse used by writers of abstracts. It is equally necessary to stress that, despite the interest of various researchers to determine the mechanisms of persuasion used in abstracts, systematic and ground-breaking studies have not yet been done on this topic. Furthermore, researchers like García-Calvo $(1999,2000)$ have already suggested that there may be cultural and disciplinary differences in the styles of persuasion used in abstracts. However, these differences have not been thoroughly investigated for this type of texts.

There are additional reasons for doing an intercultural and interdisciplinary study on the use of metadiscourse in abstracts. In the first place, it would provide information on the uses of metadiscourse in different cultures. In addition, such a study would allow us to understand the use of metadiscourse as a persuasion strategy, in order to write better, more effective abstracts.

An intercultural and interdisciplinary study of the metadiscourse used in conference abstracts can include the following questions: Does the use of metadiscourse have a universal character? Are there cultural variations in the use of metadiscourse? Do English-speaking and Spanish-speaking writers use the same types of metadiscourse? What influence may the language in which the abstract is written have on the use of metadiscourse? In addition, will the discipline or area of research of the abstract have any influence on the metadiscourse used by the writer? Is there a relationship between the language of the abstract and the area of research with regard to the use of metadiscourse?

2 More recent research by these authors has included studies done with other academia texts.

3 Textual metadiscourse include the use of logical connectives, topic markers, and illocutionary markers, among others. 
In order to provide some answers to these questions, this study sought to determine the cultural and disciplinary variations in the use of metadiscourse in research abstracts for scientific events, in light of the variables language (English or Spanish) and area of research (Linguistics and Bioscience).

\section{Methodology}

The corpus: the corpus for this study consisted of 400 abstracts, chosen at random from the texts in twelve Books of Abstracts of scientific conferences and congresses. The corpus was separated into four groups in the following way:

a. 100 abstracts written in Spanish in the area of Linguistics.

b. 100 abstracts written in Spanish in the area of Bioscience.

c. 100 abstracts written in English in the area of Linguistics.

d. 100 abstracts written in English in the area of Bioscience.

The texts in Spanish came from conferences held in Venezuela, while the texts in English came from international events. ${ }^{4}$

The categories of analysis: the corpus was analyzed by examining the writer's use of interpersonal metadiscourse. According to the classification proposed by Crismore et al. (1993), the categories of interpersonal metadiscourse are: (a) hedges, (b) certainty markers, (c) attributors, (d) attitudinal markers, and (e) commentary. What follows is a description of each category:

1. Hedges: in this study, they refer to the linguistic elements used by the writer to show his/her lack of commitment with the propositions written in the text. Examples of these linguistic elements are: the Spanish and English modals, such as can, could, may and might; the use of the conditional in Spanish and of the hypothetical would in English; and the verbs of cognition to think, to feel, to suppose), when they are used to show that the writer is not sure of the truth of his/her statements.

4 The Spanish texts appeared in the Book of Abstracts of a Venezuelan scientific event for the period between 1994 and 2000. The English texts appeared in the Book of Abstracts for twelve different scientific events which took place between 1996 and 1999 in the United States, New Zealand, Germany, Great Britain, Canada, and Australia. 
2. Certainty markers: these are the linguistic elements used to show a total conviction that a proposition is true. This category includes adverbs and phrases like absolutely sure, I am sure of.

3. Attributors: these are the references to the experts that the writer uses to give intellectual or persuasive force to his/her statements, and to support his/her arguments. An example would be "According to Benveniste..."

4. Attitudinal markers: this type of linguistic elements is used to show the writer's attitude with regard to the information presented in the text: expressions of surprise (e.g., It is incredible), expressions to show the importance of a proposition (It is very important), expressions to show agreement/disagreement (I agree/disagree) ${ }^{5}$

5. Commentary: it can include the writer's words directed to the reader, like As a colleague, and Think about, and questions directed to the reader, as well as the writer's comments to expand the information presented or to show the importance of a point in particular.

It is important to notice that, according to studies by Williams (1989) and Crismore and Farnsworth $(1989,1990)$, the writers of scientific texts who wanted to persuade their audience, using logical, ethical, and emotional arguments, tended to use a bigger amount of interpersonal metadiscourse than other types (e.g., textual metadiscourse). Because the corpus for this study consisted of texts for scientific events, it was decided that only interpersonal metadiscourse would be analyzed.

\section{Procedures}

1. Identification and length of the texts: for each group, the texts were numbered from one to one hundred. The number of words in each text was counted, to determine its length. In addition, each text was typed in a box, the same size for all abstracts, to make it easier to identify the quantity of metadiscourse elements per line.

5 The modal verbs of obligation (must, should) are also included in this category. 
GARCÍA-CALVO, J. Uses of metadiscourse in research abstracts...

2. Use of metadiscourse: each text was analyzed on the basis of the five categories of analysis. The following codes were used: H (hedges), CM (certainty markers), A (attributors), AM (attitudinal markers), and $\mathrm{C}$ (commentary). The texts were additionally coded by four independent experts: two native speakers of Spanish for the abstracts in that language, and two native speakers of English for the rest of the abstracts. The discrepancies that came up were discussed with the investigator to arrive at consent.

The density of use per line for each of the interpersonal metadiscourse categories was also determined. Likewise, the percentage of metadiscourse used was calculated for each category.

\section{Results}

The mean for written lines per abstract was 24.22 (with a range of 12 to 35 lines), with Spanish and English texts showing a similar average of lines per text. The total number of metadiscourse items for the whole corpus was 848 (with a range of 0 to 12 items per text). It was observed that all the writers used at least one type of interpersonal metadiscourse.

Table 1 shows that the total density of metadiscourse markers per line was 219 , which means that the writers of abstracts used an average of one item of interpersonal metadiscourse for every five lines. Based on both density per line and total percentage of metadiscourse used, we find that the authors preferred three types of interpersonal metadiscourse: hedges, certainty markers and attitudinal markers, in that order, followed by attributors and commentary.

TABLE 1 - USE OF INTERPERSONAL METADISCOURSE BASED ON DENSITY PER LINE AND TOTAL PERCENTAGE OF METADISCOURSE FOR THE CORPUS

\begin{tabular}{lcccccc}
\hline & Hedges & $\begin{array}{l}\text { Certainty } \\
\text { markers }\end{array}$ & $\begin{array}{l}\text { Attitudinal } \\
\text { markers }\end{array}$ & Attributors & Commentary & Total \\
\hline $\begin{array}{l}\text { Number of } \\
\text { items }(\mathrm{N})\end{array}$ & 301 & 290 & 232 & 13 & 12 & 848 \\
\hline $\begin{array}{l}\text { Density per } \\
\text { line }\end{array}$ & .078 & .074 & .062 & .003 & .002 & .219 \\
\hline $\begin{array}{l}\text { Total } \\
\text { percentage of } \\
\text { discourse }\end{array}$ & 35.49 & 34.19 & 27.36 & 1.55 & 1.41 & 100.00 \\
\hline
\end{tabular}


When we compare the texts according to language (Spanish or English), we find some important similarities and differences in the use of metadiscourse. Table 2 shows the quantity of metadiscoursive items for both languages, their density per line and the total percentage of metadiscourse used for each of the five categories. It is observed that the writers of the texts in English used a higher density of metadiscourse items per line (.247) than the authors who wrote in Spanish (.177). In relation to each of the categories, the table points out that the texts in English evidence more use of hedges that the texts in Spanish, while the latter show a bigger quantity of certainty markers that the texts in English. In relation to the use of attitudinal markers, a similar percentage was observed in the two groups of texts. It was also detected that the last two categories of interpersonal metadiscourse (attributors and commentary) are very seldom used by the writers.

TABLE 2 - COMPARISON OF USE OF METADISCOURSE BASED ON DENSITY PER LINE AND TOTAL PERCENTAGE OF METADISCOURSE FOR THE TEXTS IN ENGLISH AND IN SPANISH

\begin{tabular}{|c|c|c|c|c|c|c|}
\hline & \multicolumn{3}{|c|}{ Texts in English } & \multicolumn{3}{|c|}{ Texts in Spanish } \\
\hline & $\mathrm{N}$ & Density & $\%$ & $\mathbf{N}$ & Density & $\%$ \\
\hline Hedges & 216 & .107 & 42.86 & 85 & .045 & 24.71 \\
\hline Certainty markers & 130 & .062 & 25.79 & 160 & .082 & 46.51 \\
\hline Attitudinal markers & 140 & .072 & 27.79 & 92 & .047 & 26.74 \\
\hline Attributors & 9 & .003 & 1.78 & 3 & .001 & 1.16 \\
\hline Commentary & 9 & .003 & 1.78 & 4 & .001 & .88 \\
\hline Total Metadiscourse & 504 & .247 & 100.00 & 344 & .177 & 100.00 \\
\hline
\end{tabular}

The comparison of the texts with regard to the discipline or area of research to which they belong provides additional information on the variations of use of metadiscourse for the corpus. Table 3 compares the texts in the area of Linguistics with the Bioscience texts. This table shows that the writers of the texts in the area of Linguistics used a higher density of hedges per line (.089) than the writers of the texts in Bioscience (.063). On the other hand, the texts in Bioscience contain a higher density of certainty markers (0.92) that the texts in Linguistics (0.51). In addition, the texts in both disciplines used a similar percentage of attitudinal markers (25.00\% for Linguistics and $29.39 \%$ for Bioscience). In relation to the categories of Attributors and Commentary, it is again clear that they are scarcely used by the writers; it was even observed that attributors were absent in the Bioscience texts. 
GARCÍA-CALVO, J. Uses of metadiscourse in research abstracts...

TABLE 3 - COMPARISON OF USE OF METADISCOURSE BASED ON DENSITY PER LINE AND TOTAL PERCENTAGE OF METADISCOURSE FOR THE TEXTS IN LINGUISTICS AND BIOSCIENCE

\begin{tabular}{|c|c|c|c|c|c|c|}
\hline & \multicolumn{3}{|c|}{ Texts in Linguistics } & \multicolumn{3}{|c|}{ Texts in Bioscience } \\
\hline & $\mathbf{N}$ & Density & $\%$ & $\mathbf{N}$ & Density & $\%$ \\
\hline Hedges & 170 & .089 & 43.37 & 129 & .063 & 28.29 \\
\hline Certainty markers & 101 & .051 & 25.76 & 191 & .092 & 41.88 \\
\hline Attitudinal markers & 98 & .052 & 25.00 & 134 & .066 & 29.39 \\
\hline Attributors & 13 & .005 & 3.32 & 0 & .000 & 0.00 \\
\hline Commentary & 10 & .003 & 2.55 & 2 & .001 & .44 \\
\hline Total Metadisc & 392 & .020 & 100.00 & 456 & .222 & 100.00 \\
\hline
\end{tabular}

The similarities and differences between the abstracts become more evident and precise if we compare the use of metadiscourse in each of the subcorpora (Spanish/Linguistics, English/Linguistics, Spanish/Bioscience, and English/ Bioscience). Table 4 presents the variations of interpersonal metadiscourse based on density per line and total percentage for the four groups of texts.

These results indicate that, of the four groups, the authors of the English/ Bioscience texts used the highest quantity of interpersonal metadiscourse, based on density per line (.267), while the authors of the Spanish/Linguistics texts used the lowest quantity (.171). We also observe that the Spanish/Linguistics texts concentrate similar amounts of hedges, certainty markers and attitudinal markers (density .055 , .057 and .055 , in that order). The same phenomenon occurs in the use of hedges (.094) and attitudinal markers (.096) for the English/Bioscience subcorpora, in the use of certainty markers (.046) and attitudinal markers (.050) in the English/ Linguistics texts, and in the use of hedges (.036) and attitudinal markers (.040) in the Spanish/Bioscience abstracts. 
GARCÍA-CALVO, J. Uses of metadiscourse in research abstracts...

TABLE 4 - VARIATIONS OF USE OF METADISCOURSE BASED ON DENSITY PER LINE AND TOTAL PERCENTAGE OF METADISCOURSE FOR THE FOUR SUBCORPORA

\begin{tabular}{lrrrrrrrr}
\hline & \multicolumn{3}{c}{ Spanish/Linguistics } & & \multicolumn{3}{c}{ English/Linguistics } \\
\cline { 2 - 3 } & $\mathrm{N}$ & Density & $\%$ & & $\mathrm{~N}$ & Density & $\%$ \\
\hline Hedges & 50 & .055 & 32.05 & 122 & .121 & 52.59 \\
Certainty markers & 52 & .057 & 33.33 & 47 & .046 & 20.27 \\
Attitudinal markers & 50 & .055 & 32.05 & 51 & .050 & 21.98 \\
Attributors & 4 & .004 & 2.56 & 6 & .006 & 2.58 \\
Commentary & 0 & .000 & 0.00 & 6 & .006 & 2.58 \\
\hline Total Metadiscourse & 156 & .171 & 100.00 & 232 & .229 & 100.00 \\
\hline
\end{tabular}

\begin{tabular}{|c|c|c|c|c|c|c|}
\hline & \multicolumn{3}{|c|}{ Spanish/Bioscience } & \multicolumn{3}{|c|}{ English/Bioscience } \\
\hline & $\mathrm{N}$ & Density & $\%$ & $\mathbf{N}$ & Density & $\%$ \\
\hline Hedges & 38 & .036 & 20.00 & 96 & .094 & 34.88 \\
\hline Certainty markers & 108 & .103 & 56.84 & 79 & .079 & 29.46 \\
\hline Attitudinal markers & 42 & .040 & 22.11 & 95 & .096 & 35.66 \\
\hline Attributors & 0 & .000 & 0.00 & 0 & .000 & 0.00 \\
\hline Commentary & 2 & .002 & 1.05 & 0 & .000 & 0.00 \\
\hline Total Metadiscourse & 190 & .181 & 100.00 & 270 & .267 & 100.00 \\
\hline
\end{tabular}

If we compare the use of each metadiscourse category separately, we find additional similarities and differences. The analysis of the use of hedges shows that the texts in the English/Linguistics subcorpus present the highest density per line of the four subcorpora (.121) for this category, followed by the English/Bioscience texts (.094), while the Spanish/Bioscience texts showed the lowest density of hedges per line (.036).

When we analyze the presence of certainty markers in the corpus, we observed that the authors of the Spanish/Bioscience texts used the highest quantity per line (.103) and the writers of the English/Linguistics texts the lowest (.046).

As to the use of attitudinal markers, the English/Bioscience texts present the highest density per line (.096), while the texts in the area of Linguistics show a similar density (Spanish/Linguistics: .055 and English/Linguistics: .050). 
Table 5 summarizes the results, presenting the ranking of each subcorpora, based on density of metadiscourse items per line. We can see that the authors of the texts in English used the largest amount of total metadiscourse items. In addition, the English/Linguistics texts showed the biggest quantity of hedges, attributors and commentary. On the other hand, the authors of the texts in Spanish used the smallest quantity of total metadiscourse items, while the Spanish/Bioscience abstracts contain the least amount of hedges, attitudinal markers, and attributors. Furthermore, certainty markers seem to be more common in the Biosciences than in Linguistics, while the opposite is true for attributors.

TABLE 5 - RANKING OF THE SUBCORPORA ACCORDING TO THE USE OF METADISCOURSE BASED ON DENSITY PER LINE

Total Metadiscourse Hedges Certainty markers

English/Bioscience

English/Linguistics

Spanish/Bioscience

Spanish/Linguistics
English/Linguistics English/Bioscience Spanish/Linguistics Spanish/Bioscience
Spanish/Bioscience

English/Bioscience

Spanish/Linguistics

English/Linguistics
Attitudinal markers Attributors

English/Bioscience

Spanish/Linguistics

English/Linguistics

Spanish/Bioscience
English/Linguistics

Spanish/Linguistics

English/Bioscience

Spanish/Bioscience
Commentary

English/Linguistics

Spanish/Bioscience

English/Bioscience

Spanish/Linguistics

\section{Discussion}

Because the writers of the abstracts used almost all of the categories of interpersonal metadiscourse analyzed in this study, the results of this study seem to support the idea that the use of interpersonal metadiscourse is common in abstracts for scientific events. The results also suggest that the authors who wrote in English might consider the use of interpersonal metadiscourse as more important than the authors in Spanish, since the density of metadiscourse items in their texts was higher than the density in the texts written in Spanish. Yet, the little use of the categories Attributors and Commentary seems to imply that writers in general consider hedges, 
certainty markers and attitudinal markers as more useful persuasive resources, when they create their research abstracts.

The low frequency of the categories Attributors and Commentary in the texts can have several possible explanations. With regard to the use of attributors, the authors of the abstracts seemed to prefer making references to their own research, as a persuasive strategy, rather than mentioning the work or ideas of experts in their research area. It can also be argued that space constraints imposed by the very nature of the abstract impedes writers from making a lot of references to authorities in the field of study.

This possible explanation can also be applied to the minimal use of the category Commentary in the texts, since the limitation on the number of words that is usually recommended internationally for an abstract ( 250 words) would leave few opportunities for the writer to interact with the reader, through questions, rhetorical questions, and commentaries about what he/she writes.

The data obtained also suggest that there may be a relationship between the variables area of research and language used and the appearance of interpersonal metadiscourse in the texts. In this respect, Tables 2 and 3 indicated that there are both cultural differences, based on the language used in the texts, and disciplinary differences, based on the area of research, in relation to the use of hedges and certainty markers. On the other hand, similarities are appreciated in the use of the other three categories of interpersonal metadiscourse, when language or discipline is considered.

It is useful to try to find explanations for the differences observed in the use of hedges and certainty markers. It should be remembered that, when the texts were compared with regard to area of research (Linguistics and Bioscience, Table 3), it was evident that the authors of the texts in Linguistics used a more evasive language that the researchers in Bioscience (density .089 and .063 , in that order). With regard to this finding, researchers like Myers (1989) and Salager-Meyer (1993) have proposed that hedging is common in scientific language, both to show caution and modesty with regard to the results obtained in a study, and to represent the knowledge one has about a phenomenon more faithfully. Based on this idea, we may have hypothesized that writers in Bioscience and Linguistics should have used equal amounts of hedging, being both areas scientific disciplines. This was not the case in our study. In fact, the researchers in Bioscience used a higher density of certainty markers per line (.092), as opposed to hedges, than the researchers in Linguistics (.051). One could speculate that the investigators in Bioscience are more certain of the results of their studies, and therefore dare make stronger statements than their counterparts in Linguistics. However, Table 2 points out us that the use of hedges seems to be also related to the language 
the abstract was written in: the texts in English present a more evasive language (density .107) that the texts in Spanish (.045).

One of the reasons for this situation could be that English is a language that promotes humility and caution in written expression, while in Spanish certainty is more valued, which would represent a cultural difference in the way propositions are expressed in each language. ${ }^{6}$ Another explanation could be that formal education in English speaking countries includes the overt learning of hedging as a persuasive strategy, while Hispanic cultures emphasize the use of a more assertive language. In any case, the results of this study suggest that cultural differences exist with regard to what is considered appropriate in a communicative situation.

\section{Implications}

The results of this study have several pedagogical implications. In the first place, it can be proposed that researchers would benefit from training in writing strategies that includes the use of metadiscourse. This recommendation would be particularly aimed at Hispanic researchers who wish to express themselves in written English, since, in our experience, writing manuals in Spanish rarely include activities to familiarize students with the use of hedges and attitudinal markers. ${ }^{7}$ This situation is also common outside the Hispanic culture. Crismore, Markkanen and Steffensen (1993) have argued that neither the writing courses nor the textbooks written in English explicitly train students on the use of metadiscourse in written texts.

Likewise, researchers writing in Spanish and other Romance languages must learn how to use and control metadiscourse to elaborate more persuasive texts. They also have to realize that, if they want to be part of the larger international scientific community, which communicates almost exclusively in English, they must adjust to the styles of metadiscourse used in Anglo-Saxon cultures. Learning to use metadiscourse in persuasive texts like research abstracts involves, on one hand, deciding if metadiscourse should be used, and if so, what categories to use; and on the other, learning that this use of metadiscourse will depend on the communicative situation in which the researcher is involved, and on the discourse community or culture in which he/she lives.

6 This is an area worth investigating further.

7 The recommendation equally applies to Portuguese and other romance languages. 
This study represents a first step towards understanding the effects of culture and research area on the use of metadiscourse in abstracts for scientific events. Additional studies should include the analysis of metadiscourse in other persuasive texts and in different communicative situations, as well as the comparison of the use of metadiscourse by amateur and professional writers.

\section{RESUMO}

A finalidade deste estudo foi destacar as variações culturais e disciplinares no uso do metadiscurso em resumos de pesquisa para eventos científicos, redigidos em espanhol e em inglês. $O$ corpus está constituído de 400 resumos das várias conferências nacionais e internacionais nas áreas de Lingüistica e de Biociência. A análise dos textos foi baseada na classificação do metadiscurso proposta por Crismore et al. (1993), e fez exame do uso dos seguintes tipos de metadiscurso interpessoal: "hedges", marcadores de certeza, atributivos, marcadores de atitude, e comentário. Os resultados indicam que os tipos mais freqüentes de metadiscurso interpessoal usados no corpus foram "hedges", marcadores de certeza e marcadores de atitude. Entretanto, parece existir um relacionamento entre a língua do resumo e o uso do metadiscurso, e entre a área de pesquisa e o uso de categorias metadiscursivas. As implicações pedagógicas são apresentadas.

Palavras-chave: Resumos, pesquisa, metadiscurso.

\section{ABSTRACT}

The purpose of this study was to investigate the cultural and disciplinary variations in the use of metadiscourse in research abstracts for scientific events, written in Spanish and English. The corpus consists of 80 abstracts, from different national and international conferences, in the areas of Linguistics and Bioscience. The analysis of the texts was based on the classification of metadiscourse proposed by Crismore et al. (1993), and took into account the use of the following types of interpersonal metadiscourse: hedges, certainty markers, attributors, attitudinal markers, and commentary. The results indicate that the most common types of interpersonal metadiscourse used in the corpus were hedges, certainty markers and attitudinal markers. However, there appears to be a relationship between the language of the abstract and the use of metadiscourse, and between the area of research and the use of metadiscursive categories. Pedagogical implications are then presented.

Key-words: Abstracts, research, metadiscourse. 


\section{REFERENCES}

BOLÍVAR, A. Los resúmenes para conferencia en Lingüística Aplicada en América Latina. In: INTERNATIONAL COLLOQUIUM OF APPLIED LINGUISTICS TEXT LINGUISTICS: PRODUCTION OF TEXTS, 1., 1996, Cordoba. Paper... Cordoba, Argentina: [s.n.], 1996.

BOLÍVAR, A. Interaction through abstracts in ESP. In: MEYER, F; BOLIVAR, A.; FEBRES, J.; BONETT DE SERRA, M. (Eds.). ESP in Latin America. Mérida, Venezuela: Universidad de Los Andes, 1997a.

BOLfVAR, A. La pragmática de los resúmenes para congresos intemacionales. In: JORNADAS 50 ANIVERSARIO DEL INSTITUTO DE FILOLOGÍA ANDRÉS BELLO,1997, Caracas. Paper... Caracas: [s.n.], 1997 b.

BOLIVAR, A. Homogeneidad versus variedad en la estructura de los resúmenes de investigación para congresos. In: JORNADAS DE INVESTIGACIÓN HUMANISTICA Y EDUCATIVA, 6. 1998, Caracas. Paper... Caracas: [s.n.], 1998.

CRISMORE, A.; FARNSWORTH, R. Mr. Darwin and his readers: exploring interpersonal metadiscurse as a dimension of ethos. Rhetoric Review, v. 8, p. 91-112, 1989.

CRISMORE, A.; FARNSWORTH, R. Metadiscourse in popular and professional discourse. In: NASH, W. (Ed.). The writing scholar: studies in the language and conventions of academic discourse. Newbury Park, CA: Sage, 1990.

CRISMORE, A.; MARKKANEN, R.; STEFFENSEN, M. Metadiscourse in persuasive writing: a study of texts written by American and finnish university students. Written Communication, v. 10, n. 1, p. $39-71,1993$.

DAY, R. How to write and publish a scientific paper. Phoenix, AR: Oryx Press, 1988.

GARCÍA-CALVO, J. El análisis lingüístico y semántico del resumen para congresos: biociencias y lingüística en la AsoVAC. In: CONVENCIÓN ANUAL DE LA ASOVAC, 47., 1997, Valencia. Paper... Valencia, Venezuela: [s.n.], 1997.

GARCIA-CALVO, J. Un estudio comparativo de abstracts para eventos cientificos en ingles y español. Revista de Documentaçâo de Estudos em Lingüística Teórica e Aplicada, v. 15, n. 2, p. 269-288, 1999.

GARCIA-CALVO, J. El discurso de los académicos: un análisis de los abstracts para congresos. Unpublished paper. Caracas: Universidad Central de Venezuela, 2000.

GARTLAND, J. Medical writing and communicating. Annapolis: University Publishing Group, 1993.

GRAETZ, N. Teaching EFL students to extract structural information from abstracts. In: ULIJN, J. M.; PUGH, A. K. (Eds.). Reading for professional purposes: methods and materials in teaching language. Leuven, Belgium: Acco, 1995. 
HARTLEY, A. Computer-stimulated acquisition of reading ability in LSP. In: CORNU, A. M.; VANPARIJS, J.; DELAHAYE, M.; BATEN, L.(Eds.). Beads or bracelet? How do we approach LSP? Oxford: Oxford University Press, 1987.

HARVEY, A. A macrostructure analysis of 20 computer data-based abstracts in the field of engineering. In: SEMINARIO NACIONAL DE LENGUAS CON FINES ESPECÍFICOS, 1986, Santiago. Paper... Santiago, Chile: Universidad Católica, 1986.

KAPLAN, R. et al. On abstract writing. Text, v. 14, n. 3, p. 401-426, 1994.

MYERS, G. The pragmatics of politeness in scientific articles. Applied Linguistics, v. 10, p. 1-35, 1989.

SALAGER-MEYER, F. Discoursal flaws in medical English abstracts: a genre analysis per research type and text type. Text, v. 10, n. 3, p. 365-384, 1990.

SALAGER-MEYER, F. Medical English abstracts: how well-structured are they? Journal of American Society for Information, v. 42, p. 14-27, 1991.

SALAGER-MEYER, F. A text type and move analysis study of verb tense and modality distribution in medical English abstracts. English for Specific Purposes, v. 12, n. 2, p. 107-124, 1992.

SALAGER-MEYER, F. Hedges and textual communicative function in medical English written discourse. English for Specific Purposes, v. 13, n. 2, p. 149-170, 1993.

WILLIAMS, J. Style: ten lessons in clarity and grace. Boston: Scott Foresman, 1989. 